$\begin{array}{lcl}\text { Bentham OPEN } & \text { The Open PSychology Journal } \\ \text { CrossMark } & \text { Content list available at: www.benthamopen.com/TOPSYJ/ } \\ \text { DOI: } 10.2174 / 1874350101811010015 & \text { The } \\ \text { Open Psychology } \\ \text { lournal }\end{array}$

REVIEW ARTICLE

\title{
Relationships Between the Early Development of Drawing and Language: The Role of Executive Functions and Working Memory
}

\author{
Sabrina Panesi ${ }^{1,2, *}$ and Sergio Morra ${ }^{1}$ \\ ${ }^{I}$ Department of Education, University of Genoa, Genoa, Italy \\ ${ }^{2}$ CNR, Institute for Educational Technology, Genoa, Italy
}

\begin{abstract}
:
Background:

Extensive research examined the development of both language and drawing, but the relationship between these symbolic representation systems is less investigated and controversial. Working memory and executive functions seem to be involved in the acquisition of both drawing and language, but how they are involved in the relation between language and drawing is still unclear.
\end{abstract}

\section{Objective:}

This article reviews the relevant literature and, as a synthesis, outlines a set of models that future research could use to specify the developmental relations between language, drawing, working memory, and executive functions.

\section{Drawing and Language:}

Four theoretical positions are discussed: (a) drawing and language emerge from the same general-domain symbolic resource; (b) drawing and language as two independent systems; (c) drawing as a form of language (d) drawing influenced by language.

\section{Executive Functions and Working Memory:}

The literature on the role of executive functions and working memory in the development of either drawing or language is rather fragmentary, but on the whole, it indicates that these domain-general cognitive resources and abilities are involved in supporting the development of these representation systems. An ongoing controversy on the structure of executive functions in early childhood adds further complexity to the debate on their role.

\section{Conclusions:}

A set of models is outlined that systematically embodies the different theoretical views regarding (a) executive function development and (b) the relations of drawing development with language, executive function, and working memory. Future research can benefit from explicit models of the causal relations between these aspects of cognitive development.

Keywords: Drawing, Language, Symbolic representation, Working memory, Executive functions, Development, Young children.

\section{INTRODUCTION}

What relation is there between the early development of drawing and language? How does the overall development of the cognitive system affect language and drawing development?

Many studies investigated the development of different representational systems, such as drawing and language, but the relations between them have received less attention. Also, a number of studies argued that Working Memory

\footnotetext{
* Address correspondence to this author at the DISFOR (Department of Education), University of Genoa, Dr. Sabrina Panesi, Corso A. Podestà 2,
} 16128 Genoa, Italy; Tel: +390106475682; E-mail: sabrina.panesi@edu.unige.it 
(WM) and Executive Functions (EF) contribute to the early development of each representational system, drawing or language. However, it is still unclear whether the relation between language and drawing development is mediated by a shared cognitive structure.

This article offers a selective review of the literature that considers the relationships between the development of drawing, language, and their cognitive underpinnings. In the final section, we outline a number of alternative frame models that researchers may use to specify the causal relations between these different aspects of early cognitive development.

\section{DRAWING AND LANGUAGE}

Already in the first years of life, children are in contact with symbolic representations, and language and drawing are among the first representational systems that develop. There is a long-standing tradition of research investigating the early development of language [1 - 6] and drawing [7 - 10], but their relationship has received less attention.

Comparing the emergence of graphic symbolism and language, we can consider that representational drawing emerges later, around three years of age [11 - 13], whereas the first words appear around the first year [14]; in particular, Callaghan [11] suggested that children understand the symbolic nature of pictures before being able to produce them. Adamson [14] instead claimed that language comprehension starts around 9 to 10 months of age, and language production starts around the first half of the second year.

Regarding language production, Piaget [5] argued that children can use language symbolically when they use words to denote absent objects, substituting information in one modality (i.e. sounds) for information in a different modality (e.g., a visually seen or tactually felt object). However, infants can produce a range of language-like sounds early in the first year. Graphic production, in contrast, requires eye-hand coordination and a fine-tuned pincer grasp that is necessary to manipulate the tools of drawing. Both of these skills are not sufficiently refined until the second year of life [15]; only subsequently can children produce representational drawings.

It would be desirable to consider the brain structures upon which language and drawing development rely. However, this aspect can only be considered with great caution. First, the young child's brain develops with great plasticity; the process of modularization, including the modular structure of language, is far from being complete [16 - 18], and brain lateralization undergoes developmental changes as a function of experience and automatization of processes [19]. Second, at present, it would be difficult to use brain imaging techniques in studies of drawing tasks, because the drawing activity would inevitably produce large movement artifacts; consequently, little evidence is available on the brain structures that underlie drawing development. More evidence is available on language, however. For instance, Friederici reported that, in ERP studies, 14-month-olds already show an enhanced N400 response when presented with words that are incongruous with a picture, and at 19 months this effect also appears for phonotactically legal nonwords; however, the distribution of this semantic N400 effect in young children seems to be more frontal than in adults [20]. Walton et al. reported that phonological awareness was correlated, in 3- to 5-year-olds, with diffusion parameters (obtained from MRI) in bilateral ventral white matter pathways and the corpus callosum. From this, they concluded that the relationships found in the left hemisphere indicate that structural markers of language processing found in older children and adults are already present in 3-year-olds, whereas the right hemisphere findings do not correspond with common adults findings. They suggest that the language processing network in children is more extended than in adults, and becomes more specialized in the course of development [21]. Rosselli et al. [22] reviewed the literature on the brain bases of language development and concluded that, in language tasks, the brain activation undergoes a change from bilateral in young children to unilateral in adults. "Although data point to an asymmetrical distribution of language from birth, lateralization of language in the left hemisphere is modified by experience and ... greater lateralization of language in the left hemisphere seems to be an index of maturation." (p.16).

There is one neuropsychological study of children's drawing that could be related to these studies of language development. Stiles et al. reported that children with congenital focal injuries to the right hemisphere, by the age of 5 or at most 6, can produce simple drawings of a house, but they rely heavily on stereotyped graphic formulae, and also when they grow older they find it difficult to alter on request the structure of their graphic productions [23]. This suggests that the left hemisphere could handle schematic formulae to represent graphically object categories, such as houses; but an efficient right hemisphere would be required to be able to modify those simple graphic schemes and enrich them with contextually relevant detail. We might suggest (given the finding discussed above that language in preschoolers' brains is already lateralized, at least partly, in the left hemisphere) that language representations could 
support the formation of early, simple graphic schemes, but not the modification of those schemes to produce representations that go beyond categorical information.

Besides considering that drawing chronologically develops after language, we must focus on the cognitive aspects of the relationship between the two representational systems. In the literature, we can find four principal lines of thought: (1) drawing and language as signifying systems that emerge from the same domain-general symbolic resource; (2) drawing and language as two different systems that develop independently of each other; (3) drawing as a form of language (4) drawing influenced by language.

The first position reflects principally Piaget's view [5, 24] that considered drawing and language as two forms of manifestation of a more general symbolic function, along with mental imagery and symbolic play. He argued that in the first phase of development (sensory-motor period, until $1 \frac{1}{2}$ years) infants cannot evoke an absent object and there is no real difference between signifier and signified. In the preoperational period (2-7 years) children develop the symbolic function. In this perspective, drawing and language are two signifying systems that emerge from the same domaingeneral symbolic resource starting from two years.

In contrast, the second position reflects Paivio's [25] dual-coding theory, which claims that visual and verbal information are processed separately and along different channels so that the human mind is endowed with distinct representations for information processed in each channel. From a different point of view, Chomsky's [3] argument that language development is based on a particular Language Acquisition Device is consistent with the idea of separate development, because the specific and innate mechanisms of language development would be very different from the mechanisms used for the development of visual imagery and motor skills.

The third line of thought sees drawing as a form of language [26 - 28]. Willats [26] argued that children initially use their picture primitives (dots, lines, areas) to represent objects globally; then they use such primitives to construct meaningful basic schemes, and finally they arrange those schemes in space, using syntactic rules of adjacency, projection, and occlusion. It seems that, just as children begin to speak playing with phonemes, and only later they produce words and sentences, in the same way drawing starts with scribbling, which lays the foundations for graphic production [8, 13], and only subsequently children combine graphic elements to create more complex graphic representations. Following this perspective, Cohn [26, 27] speaks of "visual lexical items" of drawing. In particular, he argued that a "lexicon" of schematic patterns, stored in the individual's long-term memory, is the base from which drawings are built. These patterns have different levels of complexity, ranging from elementary "graphemes" (e.g., dots and lines), to parts of meaningful drawings (e.g., particular patterns used to represent an eye or a hand), schematic full drawings (e.g., a stereotypical way to draw a car or a house), and beyond that, to patterns that convey the structure of an entire scene. Furthermore, he argued that, while simple graphemes have no correspondence to meaning, more complex schemata are often meaningful because they correspond to concepts or spatial structures.

Finally, and this is the fourth of the positions listed above, some studies suggested that language can influence drawing. In particular, Callaghan [29] found that young children $\left(2 \frac{1}{2}-3\right.$ years old) use language to mediate pictorial symbol use, that is, the availability of verbal labels can facilitate the children performance in graphic symbolic tasks. Similarly, Toomela [30] argued that the development of language can be seen as a mediator for the development of drawing. A reason could be that a symbolic component of language is already present in toddlers, but symbolic graphic production emerges subsequently around three years; thus, the development from scribbling to representational drawing can be influenced by language that already has a symbolic component. Adi-Japha et al. [31] found that bilingualism facilitates drawing flexibility in preschoolers, which also suggests an influence of language on drawing.

In sum, at least three out of four lines of thought suggest a relationship between drawing and language in young children.

\section{DRAWING AND LANGUAGE: COGNITIVE UNDERPINNINGS}

Some studies have examined how the development of general abilities or domain-general components of the cognitive system affects drawing or language. In this article, we focus on the role of executive functions and working memory. The term "working memory" refers to the simultaneous maintenance and manipulation of information; it is not a synonym of "short-term memory", but points to "the small amount of information that can be held in mind and used in the execution of cognitive tasks" [32, p.197]. The term "executive functions", in Miyake's [33] classical model, refers to (a) inhibition, that is the ability to inhibit prepotent responses or misleading representations; (b) shifting, that is the ability to switch between mental sets or rules; (c) updating, that is the ability to monitor and update information in 
working memory. Miyake and colleagues [33] suggested the possibility that all executive functions rely to some extent on working memory. Other models of executive function structure have been proposed, and their developmental course is widely debated [34]. One model in particular [35] suggested that working memory and inhibition are basic attentional resources, and shifting and updating are specific processes that rely on those resources. In general, developmental research found that working memory capacity and inhibition can be reliably distinguished at about 5 years, and that shifting and updating skills differentiate later [34]. Space limitations prevent a detailed review of the physiological substratum of working memory and executive functions in young children; rather, see [36 - 39]. Suffice it here to say that the prefrontal cortex and its connections are heavily involved in these functions, and that the prefrontal cortex undergoes long-lasting maturation with deep anatomical changes during childhood and adolescence - changes that are related to behavioral evidence of developmental progress in executive function tasks.

\subsection{Drawing, Working Memory and Executive Functions}

Working memory and executive functions have a central role in cognitive development and there are several reasons to think that these cognitive components are also important in drawing development. First, working memory capacity constrains the degree of complexity and sophistication of children's solutions to pictorial problems. Second, working memory capacity sets an upper limit to performance on certain drawing tasks. Third, executive function (in particular, inhibitory control) seems to be involved in drawing tasks that require the inhibition of information that interferes with solving a pictorial problem or require to suppress a habitual drawing style [40, 41].

Morra and Panesi [42] argued that working memory capacity plays an important role already in the early development from scribbling to drawing, because its growth enables the child to put together the various components (i.e., motor, visual, spatial, semantic, symbolic skills) involved in the emergence of drawing. Other studies underlined the importance of working memory capacity in different drawing tasks also in the preschool years, when children have already developed a symbolic component in drawing. In particular, the increase of working memory capacity seems to be associated to the emerging spatial organization of drawings [43] and to drawing flexibility [44].

Dennis [43] argued that working memory and the spatial organization of drawings are correlated. In particular, she argued that children from 3 to $4 \frac{1}{2}$ years, typically with WM capacity of 1 unit, are able to arrange the features of objects (e.g., human figure), in a global, rule-bound, manner, so that the object is recognizable; and children from $4 \frac{1}{2}$ to 6 years, typically with WM capacity of 2 units, are able to spatially arrange the features of a whole set of objects into a scene which manifests higher-order organization, indicated pictorially by a foreground (e.g., by alignment on a ground line).

Other authors argued that also executive functions may aid the development of different drawing tasks. Riggs et al. [41] found that, in preschoolers, inhibitory control predicts human figure drawing development, and they explained this result in two ways: (1) inhibitory control supports drawing development by enabling children to suppress their habitual drawing style, and thus to introduce novel skills that render a topic in a more mature and sophisticated way; (2) in particular, the development of inhibitory control allows children to shift from nonrepresentational to representational human figure drawing.

On neuropsychological grounds, Kibby and colleagues showed that children with ADHD, a disorder of executive functioning, performed poorly on a clockface drawing task, and that their drawing performance correlated with a test of executive functioning, the Wisconsin Card Sorting Test [45]. Moreover, Cohen et al. [46] suggested that typically developing children, until the age of 6 or 7 , tend to neglect the upper-left quadrant in the clock drawing task because of immature development of the executive functions.

Panesi and Morra [44] also found that executive functions, together with working memory, influence the ability to modify habitual drawing schemes to draw a dog different from a human figure drawing. Working memory is decisive because a child must keep activated and coordinate, in addition to a habitual scheme, its feature(s) that need to be modified and the graphic patterns or devices that could be used to represent those modifications [40, 47]. Executive functions are involved because a child, while drawing, must inhibit her habitual way of drawing the human figure, and monitor the ongoing drawing process to optimize the changes in her habitual scheme [48].

\subsection{Language, Working Memory and Executive Functions}

The relationships between language, WM and EF have been studied especially with children with Specific Language Impairment (SLI). Neuropsychological evidence suggests that some language tasks involve the activation of 
prefrontal areas also involved in executive functions [49]. Bishop, Nation, and Patterson [50] suggest three possible models that might account for the relationship between EF and language impairments: (a) executive functions causally influence language development (i.e., efficient attentional skills aid language learning); (b) language ability causally influence EF development, possibly because children resort to verbal mediation while performing certain tasks that involve EF; (c) there are no direct causal dependencies at the cognitive level between language and EF skills, but shared genetic risk factors could account for the correlation between these skills in young children; for instance, delayed frontal lobes development might impinge on brain areas important for EF, and on adjacent areas involved in language processing.

For the purpose of this article, we only consider the first perspective (a) proposed by Bishop et al. [50]. Related to this perspective, Mirman and Britt [51] suggest a deep link between EF and language. In their review of research on lexical-semantic access deficits, they point to the possibility that EF is involved in semantic control. For instance, when a person hears a spoken word, a number of candidate lexical entries are activated; word identification requires modulating activation and inhibition, so that activation of the incorrect competitors is suppressed and the difference of their activation from the correct entry is maximized.

The impact of EF on language development was considered by Im-Bolter, Johnson, and Pascual-Leone [35]. In particular, they considered the influence of mental attention capacity, inhibition, shifting and updating on language in school-children with typical development and children with SLI. From this research, some relevant findings emerged: (1) updating mediates the relationship between mental attention capacity and language; (2) inhibition contributes indirectly to language through its relation with mental attentional capacity.

Also, studies with younger children with SLI reported their poor performance in some cognitive measures. For example, Marton [52] demonstrated that children with SLI (compared with age-matched controls) show a higher proportion of perseveration errors in shifting tasks, and poorer performance in working memory tasks with visuo-spatial (i.e., non-verbal) content.

A number of studies consider the relationships between language development and cognitive processing in young children with typical development. The most studied cognitive component in relation to language in young children seems to be inhibition. In this regard, Ibbotson and Kearvell-White [53] found that individual differences in inhibitory control predict the differences in grammatical ability. Viterbori et al. [54] found that inhibitory control predicts phonological accuracy, intelligibility, and syntactic and morphological abilities in young children. Cozzani et al. [55] demonstrated that the ability to inhibit prepotent responses is associated with competence in formulating sentences.

Associations also emerged between shifting and language. Kapa and Colombo [56] found that the preschoolers who were better able to shift their attention in the Dimensional Change Card Sort [57] were more successful language learners. Viterbori et al. [54] argued that shifting has an important role in both morphological and syntactic ability during the third year of life.

In sum, although few studies considered the joint influence of WM and EF on language in toddlers and preschoolers, there is empirical support for a relation between language and each of these components of the cognitive system in children with typical development, and for their involvement in impaired language development.

\section{IMPLICATIONS FOR FUTURE RESEARCH: HYPOTHETICAL MODELS}

In the previous sections, we discussed theories and empirical evidence regarding the relationship between drawing and language, and the relation of each of these representational systems (separately considered) with domain-general cognitive resources and processes, such as WM and EF. We think that the time is ripe for researchers to aim at proposing and testing comprehensive models of the developmental relationships between representational systems and with their cognitive underpinnings in young children. Based on the evidence reviewed in the previous sections, in this one, we discuss how such models could be framed, and we propose a set of nine alternative models, constructed by crossing systematically $3 \times 3$ alternatives in two independent conceptual dimensions.

Most studies suggest that there is a relation between drawing and language [5, 26 - 31] and in particular, in the first years of life when children pass from non-representational to representational drawing, the role of language - that has already developed a symbolic component - might be fundamental [29]. It is therefore conceivable that language influences drawing, at least at an early stage, when children are acquiring the capability for representational drawing. Furthermore, considering the relations in young children between drawing and cognitive processing [40, 42], and between language and cognitive processing $[54,55]$, it is conceivable that both drawing and language are influenced by 
WM and EF. Thus, WM and EF might influence the development of drawing and language, representing a shared cognitive underpinning that explains at least in part their common variance.

To formulate these models, we also need to consider the literature about the structure of WM and EF in young children. This is a hot and widely debated research field $[34,58]$. Some studies proposed a single factor for WM and EF $[59,60]$ and others proposed instead a two-factor model $[61,62]$ in which the two latent factors are correlated. A review of the literature [34] indicates that research with children from 2 to 4 years found support for a one-factor model; instead, most studies on older children supported a two-factor model. These findings seem to indicate that the structure of WM and EF could initially be unitary, and differentiate during the preschool years [60]. Other research, mostly carried out with older children, seems to indicate that WM, considered as a general cognitive resource, influences EF $[35,63,64]$. It is also debated whether inhibition should better be regarded as an executive function among others, or a general-purpose attentional resource that underlies all executive functions and, in a sense, unifies the field [33, 35, 63, $65]$.

Thus, considering both the possible relationships between WM and EF in young children and the possible effects of language and general cognitive resources on drawing, we can outline nine alternative models, each of which represents a combination of theoretical claims made in the literature and supported at least partly by some empirical evidence. Fig. (1) shows the nine alternative models in a $3 \times 3$ matrix.

The rows of the matrix represent three different types of relationship between WM and EF:

1. WM and EF are unitary and indistinguishable in young children (see models a, b, c).

2. WM and EF are two distinguishable but correlated latent factors (see models d, e, f).

3. WM and EF are two distinguishable latent factors and WM influences EF (see models g, h, i).

The columns represent three different ways in which language and general cognitive resources influence drawing:

1. General cognitive resources influence both language and drawing, and language influences drawing (see models $\mathrm{a}, \mathrm{d}, \mathrm{g})$.

2. General cognitive resources influence both language and drawing that are two separate representational systems (see models b, e, h).

3. General cognitive resources influence language that, in turn, influences drawing (see models c, $\mathrm{f}, \mathrm{i}$ ).
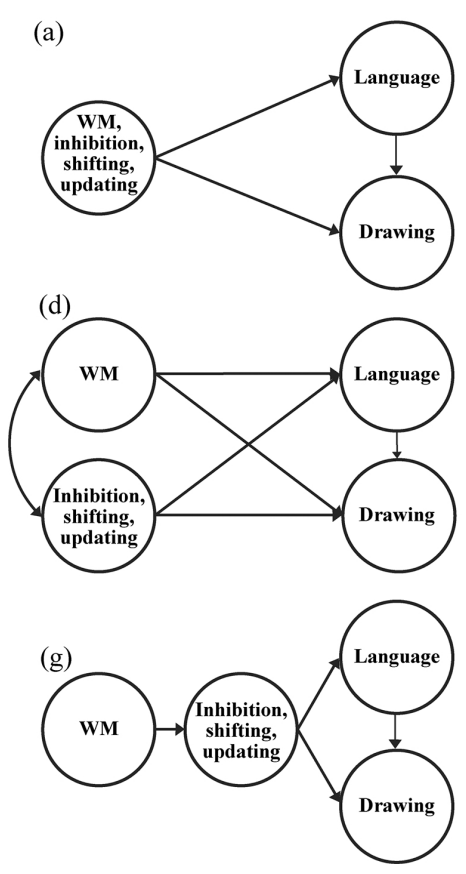

(b)
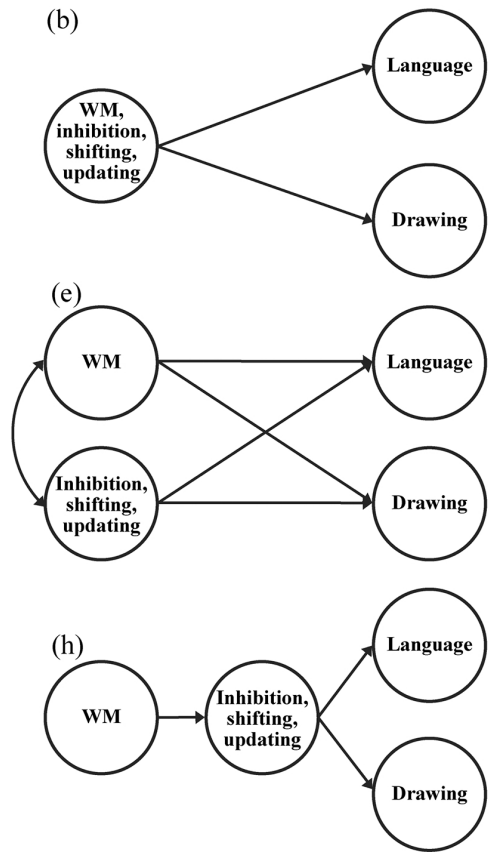

(c)

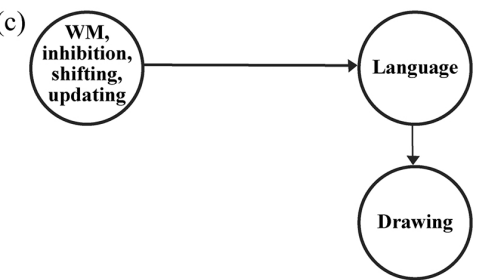

(f)
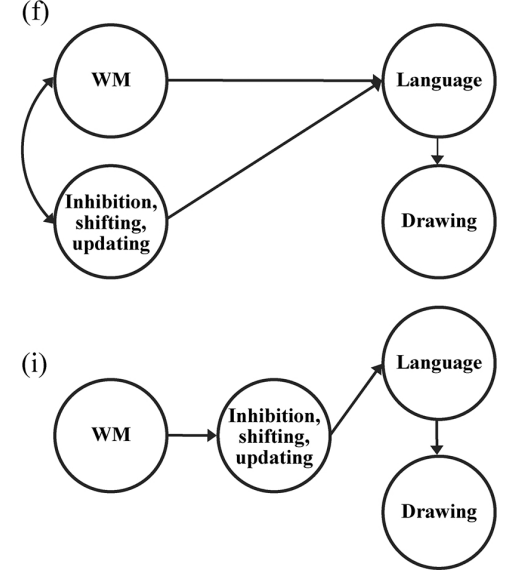

Fig. (1). Nine alternative models of the relationships among WM, EF, drawing and language in young children. 
There might not be a single model valid throughout early development, because the relationships among the considered components may change in time. Indeed, the existing evidence - albeit sparse - suggests that some models are more plausible in very young children and others in older ones. For instance, a unitary WM and EF construct (such as in the first row) may be valid for younger children, but two factors should rather be distinguished (as in the second and third row) after about age 4 or $5[34,61]$. Some evidence indicates a direct influence of language on drawing in younger children [29], but not necessarily so in older ones; also some neuropsychological evidence seems to suggest a role of language in the early acquisition of graphic schemes, but not in later and more complex achievements [23]. Also working memory capacity and executive functions seem to be involved in the early phases of drawing development [41, 42]. Consequently, model (a) would seem the most promising account of younger children's cognition. In contrast, models (e) and (h) could be more promising at about age 5. However, we formulate these suggestions with great caution, because they are only based on rather fragmentary evidence; indeed, the main point of this article is that systematic research is needed to clarify the relationship among different components of children's architecture of mind.

\section{CONCLUSION}

The first years of life are crucial for the development of representational systems, such as drawing and language, as well as for EF [58] and WM [66], but there are no studies that consider the possible relationships among all of these components in young children. In this paper, we summarized the different views proposed in the literature regarding these relationships and made them explicit in the form of nine alternative and testable models that consider the relations among basic cognitive processes (WM, inhibition, shifting and updating), drawing and language. We think that the relations between these components may change during the early years of life, considering that language can play an important role in the transition from non-representational to representational drawing, and that WM and EF could represent a shared cognitive underpinning of drawing and language, which could explain at least in part their common variance.

\section{CONSENT FOR PUBLICATION}

Both authors made substantial, direct and intellectual contributions to the conception, writing and editing of the work, and approved it for publication.

\section{CONFLICT OF INTEREST}

The authors declare no conflict of interest, financial or otherwise.

\section{ACKNOWLEDGEMENTS}

The first author is grateful to the Developmental and Educational Section of the Italian Psychological Association (A.I.P.) for a prize, awarded in 2017, which covered almost entirely the publication cost of this article.

\section{REFERENCES}

[1] Bates E, Benigni L, Bretherton I, Camaioni L, Volterra V. The emergence of symbols: Cognition and communication in infancy. New York: Academic Press 1979.

[2] Brown R. A first language: The early stages. Cambridge, MA: Harvard University Press 1973. [http://dx.doi.org/10.4159/harvard.9780674732469]

[3] Chomsky N. Current issues in linguistic theory. The Hague: Mouton 1964.

[4] Nelson K. Structure and strategy in learning to talk. Monogr Soc Res Child Dev 1973; 38(149): 1-135. [http://dx.doi.org/10.2307/1165788]

[5] Piaget J. Play, dreams, and imitation in childhood. New York: W.W. Norton \& Co 1962.

[6] Vygotsky LS. Thought and language. Cambridge, MA: MIT Press 1962. [http://dx.doi.org/10.1037/11193-000]

[7] Freeman NH. Strategies of Representation in Young Children. London: Academic Press 1980.

[8] Kellogg R. Analyzing children's art. Palo Alto, CA: Mayfield 1969.

[9] Lowenfeld V. Creative and mental growth. New York: MacMillan 1947.

[10] Luquet G. Le dissin enfantin. Parigi: Alcan 1927.

[11] Callaghan TC. Early understanding and production of graphic symbols. Child Dev 1999; 70(6): 1314-24. [http://dx.doi.org/10.1111/1467-8624.00096] [PMID: 10621958] 
[12] Cox MV. Children's drawings. Harmondsworth: Penguins 1992.

[13] Golomb C. Representation and reality: The origins and determinant of young children's drawings. Rev Res Vis Arts Educ 1981; 14 : 36-48.

[14] Adamson LB. Communication development during infancy. Boulder, CO: Westview 1995.

[15] Callaghan TC, Rankin MP. Emergence of graphic symbol functioning and the question of domain specificity: A longitudinal training study. Child Dev 2002; 73(2): 359-76. [http://dx.doi.org/10.1111/1467-8624.00412] [PMID: 11949897]

[16] Elman JL, Bates E, Johnson MH, Karmiloff-Smith A, Parisi D, Plunkett K. Rethinking innateness: A connectionist perspective on development. Cambridge, MA: MIT Press 1996.

[17] Bates E, Goodman J. On the inseparability of grammar and the lexicon: Evidence from acquisition, aphasia, and real-time processing. Lang Cogn Process 1997; 12(5-6): 507-86. [http://dx.doi.org/10.1080/016909697386628]

[18] Thomas M, Karmiloff-Smith A. Can developmental disorders reveal the component parts of the human language faculty? Lang Learn Dev 2005; 1: 65-92.

[http://dx.doi.org/10.1207/s154733411ld0101_5]

[19] Arsalidou M, Pawliw-Levac M, Sadeghi M, Pascual-Leone J. Brain areas associated with numbers and calculations in children: Meta-analyses of fMRI studies. Dev Cogn Neurosci 2017; S1878-9293(17)30010-5. [https://doi.org/10.1016/j.den.2017.08.002]. [PMID: 28844728]

[20] Friederici AD. The neural basis of language development and its impairment. Neuron 2006; 52(6): $941-52$. [http://dx.doi.org/10.1016/j.neuron.2006.12.002] [PMID: 17178399]

[21] Walton M, Dewey D, Lebel C. Brain white matter structure and language ability in preschool-aged children. Brain Lang $2018 ; 176$ : 19-25. [http://dx.doi.org/10.1016/j.bandl.2017.10.008] [PMID: 29132048]

[22] Rosselli M, Ardila A, Matute E, Vélez-Uribe I. Language development across the life span: A neuropsychological/neuroimaging perspective. Neurosci J 2014; 2014: 585237.

[http://dx.doi.org/10.1155/2014/585237] [PMID: 26317109]

[23] Stiles J, Trauner D, Engel M, Nass R. The development of drawing in children with congenital focal brain injury: Evidence for limited functional recovery. Neuropsychologia 1997; 35(3): 299-312. [http://dx.doi.org/10.1016/S0028-3932(96)00088-7] [PMID: 9051678]

[24] Piaget J, Inhelder B. The Psychology of the child. New York: Basic Books 1969.

[25] Paivio A. Imagery and Verbal Processes. New York: Holt, Rinehrt, and Winston 1971.

[26] Willats J. Drawing systems revisited: The role of denotation systems in children's figure drawing.Visual order: The nature and development of pictorial representation. Cambridge: Cambridge University Press 1985; pp. 78-100.

[27] Cohn N. Explaining "I can't draw": Parallels between the structure and development of language and drawing. Hum Development 2012; 55: $167-92$. [http://dx.doi.org/10.1159/000341842]

[28] Cohn N. Framing "I can't draw": The influence of cultural frames on the development of drawing. Cult Psychol 2014; $20(1): 102-17$. [http://dx.doi.org/10.1177/1354067X13515936]

[29] Callaghan TC. Factors affecting children's graphic symbol use in the third year. Language, similarity, and iconicity. Cogn Dev 2000; 15: $185-2014$. [http://dx.doi.org/10.1016/S0885-2014(00)00026-5]

[30] Toomela A. Drawing as a verbally mediated activity: A study of relationships between verbal, motor, and visuospatial skills and drawing in children. Int J Behav Dev 2002; 26(3): 234-47. [http://dx.doi.org/10.1080/01650250143000021]

[31] Adi-Japha E, Berberich-Artzi J, Libnawi A. Cognitive flexibility in drawings of bilingual children. Child Dev 2010; 81(5): $1356-66$. [http://dx.doi.org/10.1111/j.1467-8624.2010.01477.x] [PMID: 20840226]

[32] Cowan N. Working memory underpins cognitive development, learning, and education. Educ Psychol Rev 2014; 26(2): $197-223$. [http://dx.doi.org/10.1007/s10648-013-9246-y] [PMID: 25346585]

[33] Miyake A, Friedman NP, Emerson MJ, Witzki AH, Howerter A, Wager TD. The unity and diversity of executive functions and their contributions to complex "Frontal Lobe" tasks: A latent variable analysis. Cognit Psychol 2000; 41(1): 49-100. [http://dx.doi.org/10.1006/cogp.1999.0734] [PMID: 10945922]

[34] Morra S, Panesi S, Traverso L, Usai MC. Which tasks measure what? Reflections on executive function development and a commentary on Podjarny, Kamawar, and Andrews (2017). J Exp Child Psychol 2018; 167: 246-58. [http://dx.doi.org/10.1016/j.jecp.2017.11.004] [PMID: 29197781]

[35] Im-Bolter N, Johnson J, Pascual-Leone J. Processing limitations in children with specific language impairment: The role of executive function. Child Dev 2006; 77(6): 1822-41. [http://dx.doi.org/10.1111/j.1467-8624.2006.00976.x] [PMID: 17107463] 
[36] Diamond A. Normal development of prefrontal cortex from birth to young adulthood: Cognitive functions, anatomy, and biochemistry.Principles of Frontal Lobe Function. London: Oxford Univ. Press 2002; pp. 466-503. [http://dx.doi.org/10.1093/acprof:oso/9780195134971.003.0029]

[37] Houdé O, Rossi S, Lubin A, Joliot M. Mapping numerical processing, reading, and executive functions in the developing brain: An fMRI meta-analysis of 52 studies including 842 children. Dev Sci 2010; 13(6): 876-85. [http://dx.doi.org/10.1111/j.1467-7687.2009.00938.x] [PMID: 20977558]

[38] Moriguchi Y, Hiraki K. Prefrontal cortex and executive function in young children: a review of NIRS studies. Front Hum Neurosci 2013; 7: 867. [http://dx.doi.org/10.3389/fnhum.2013.00867] [PMID: 24381551]

[39] Bolton S, Hattie J. Cognitive and brain development: Executive function, piaget, and the prefrontal cortex. Arch Psychol 2017; 1(3): 1-36.

[40] Morra S. Memory components and control processes in children's drawing.Children's understanding and production of pictures, drawings \& art. Gottingen. Hogrefe 2008; pp. 53-86.

[41] Riggs KJ, Jolley RP, Simpson A. The role of inhibitory control in the development of human figure drawing in young children. J Exp Child Psychol 2013; 114(4): 537-42. [http://dx.doi.org/10.1016/j.jecp.2012.10.003] [PMID: 23313449]

[42] Morra S, Panesi S. From scribbling to drawing: the role of working memory. Cogn Dev 2017; 43: $142-58$ [http://dx.doi.org/10.1016/j.cogdev.2017.03.001]

[43] Dennis S. Stage and structure in the development of children's spatial representations. The mind's staircase. Earlbaum 1992; pp. 229-45.

[44] Panesi S, Morra S. Drawing a dog: The role of working memory and executive function. J Exp Child Psychol 2016; $152: 1$-11. [http://dx.doi.org/10.1016/j.jecp.2016.06.015] [PMID: 27454235]

[45] Kibby MY, Cohen MJ, Hynd GW. Clock face drawing in children with attention-deficit/hyperactivity disorder. Arch Clin Neuropsychol 2002; 17(6): 531-46. [http://dx.doi.org/10.1093/arclin/17.6.531] [PMID: 14591854]

[46] Cohen MJ, Ricci CA, Kibby MY, Edmonds JE. Developmental progression of clock face drawing in children. Child Neuropsychol 2000; 6(1): 64-76. [http://dx.doi.org/10.1076/0929-7049(200003)6:1;1-B;FT064] [PMID: 10980669]

[47] Morra S. Cognitive aspects of change in drawings: A neo-Piagetian theoretical account. Br J Dev Psychol $2005 ; 23$ : $317-41$. [http://dx.doi.org/10.1348/026151005X27182]

[48] Barlow CM, Jolley RP, White DG, Galbraith D. Rigidity in children's drawings and its relation with representational change. J Exp Child Psychol 2003; 86(2): 124-52. [http://dx.doi.org/10.1016/S0022-0965(03)00109-7] [PMID: 13129699]

[49] Vannest J, Karunanayaka PR, Schmithorst VJ, Szaflarski JP, Holland SK. Language networks in children: evidence from functional MRI studies. AJR Am J Roentgenol 2009; 192(5): 1190-6. [http://dx.doi.org/10.2214/AJR.08.2246] [PMID: 19380541]

[50] Bishop DVM, Nation K, Patterson K. When words fail us: insights into language processing from developmental and acquired disorders. Philos Trans R Soc Lond B Biol Sci 2013; 369(1634): 20120403. [http://dx.doi.org/10.1098/rstb.2012.0403] [PMID: 24324244]

[51] Mirman D, Britt AE. What we talk about when we talk about access deficits. Philos Trans R Soc Lond B Biol Sci 2013; 369(1634): 20120388. [http://dx.doi.org/10.1098/rstb.2012.0388] [PMID: 24324232]

[52] Marton K. Visuo-spatial processing and executive functions in children with specific language impairment. Int J Lang Commun Disord 2008; 43(2): 181-200. [http://dx.doi.org/10.1080/16066350701340719] [PMID: 17852522]

[53] Ibbotson P, Kearvell-White J. Inhibitory control predicts grammatical ability. PLoS One 2015; 10(12): e0145030. [http://dx.doi.org/10.1371/journal.pone.0145030] [PMID: 26659926]

[54] Viterbori P, Gandolfi E, Usai MC. Executive skills and early language development, Rivista Italiana di Psicolinguistica Applicata J App Psycho 2012; 12(3): 17-32.

[55] Cozzani F, Usai MC, Zanobini M. Linguistic abilities and executive function in the third year of life. Rivista Italiana di Psicolinguistica applicata / Journal of applied psycholinguistics 2013; 13(1): 25-43.

[56] Kapa LL, Colombo J. Executive function predicts artificial language learning. J Mem Lang 2014; 76: $237-52$. [http://dx.doi.org/10.1016/j.jml.2014.07.004] [PMID: 29129958]

[57] Zelazo PD. The Dimensional Change Card Sort (DCCS): A method of assessing executive function in children. Nat Protoc 2006; 1(1): 297-301. [http://dx.doi.org/10.1038/nprot.2006.46] [PMID: 17406248]

[58] Garon N, Bryson SE, Smith IM. Executive function in preschoolers: A review using an integrative framework. Psychol Bull 2008; 134(1): 31-60. 
[http://dx.doi.org/10.1037/0033-2909.134.1.31] [PMID: 18193994]

[59] Wiebe SA, Espy KA, Charak D. Using confirmatory factor analysis to understand executive control in preschool children: I. Latent structure. Dev Psychol 2008; 44(2): 575-87. [http://dx.doi.org/10.1037/0012-1649.44.2.575] [PMID: 18331145]

[60] Wiebe SA, Sheffield T, Nelson JM, Clark CA, Chevalier N, Espy KA. The structure of executive function in 3-year-olds. J Exp Child Psychol 2011; 108(3): 436-52.

[http://dx.doi.org/10.1016/j.jecp.2010.08.008] [PMID: 20884004]

[61] Miller MR, Giesbrecht GF, Muller U, McInerney RJ, Kerns KA. A latent variable approach to determining the structure of executive function in preschool children. J Cogn Dev 2012; 13(3): 395-423. [http://dx.doi.org/10.1080/15248372.2011.585478]

[62] Usai MC, Viterbori P, De Franchis V, Traverso L. Latent structure of executive function in five and six-year-old children: A longitudinal study. Eur J Dev Psychol 2014; 11: 447-62.

[http://dx.doi.org/10.1080/17405629.2013.840578]

[63] Agostino A, Johnson J, Pascual-Leone J. Executive functions underlying multiplicative reasoning: problem type matters. J Exp Child Psychol 2010; 105(4): 286-305.

[http://dx.doi.org/10.1016/j.jecp.2009.09.006] [PMID: 19913238]

[64] Panesi S, Morra S. La Casetta Magica. Un nuovo strumento per indagare l'aggiornamento (updating) della memoria di lavoro in età prescolare. Psicol Clin Sviluppo 2017; 21(3): 443-62. [The Magic House. A new measure of updating for pre-schoolers]. [https://doi.org/10.1449/88502].

[65] Miyake A, Friedman NP. The nature and organization of individual differences in executive functions: Four general conclusions. Curr Dir Psychol Sci 2012; 21(1): 8-14.

[http://dx.doi.org/10.1177/0963721411429458] [PMID: 22773897]

[66] Pascual-Leone J, Johnson J. A dialectical constructivist view of developmental intelligence.Handbook of understanding and measuring intelligence. Thousand Oaks, CA: Sage 2005; pp. 177-201. [http://dx.doi.org/10.4135/9781452233529.n11]

\section{(C) 2018 Panesi and Morra.}

This is an open access article distributed under the terms of the Creative Commons Attribution 4.0 International Public License (CC-BY 4.0), a copy of which is available at: (https://creativecommons.org/licenses/by/4.0/legalcode). This license permits unrestricted use, distribution, and reproduction in any medium, provided the original author and source are credited. 